\title{
What are emergency-sensitive conditions? A survey of Canadian emergency physicians and nurses
}

\author{
Simon Berthelot, $\mathrm{MD}^{*}{ }^{\dagger}$; Eddy S. Lang, $\mathrm{MD}^{\ddagger} ;$ Hude Quan, MD, PhD ${ }^{\dagger}$; Henry T. Stelfox, MD, $\mathrm{PhD}^{\dagger \S}$
}

\section{ABSTRACT}

Objective: In a previous study, we assembled a multidisciplinary Canadian panel and identified 37 International Classification of Diseases-10-Canada Diagnosis Groups (DGs) for which emergency department (ED) management may potentially reduce mortality (emergency-sensitive conditions). Before using these $37 \mathrm{DGs}$ to calculate a hospital standardized mortality ratio (HSMR) specific to emergency care, we aimed to test their face validity with ED care providers.

Methods: We conducted a self-administered web survey among Canadian emergency physicians and nurses between November 22 and December 31, 2012. All members $(N=$ 2,507 ) of the Canadian Association of Emergency Physicians and the National Emergency Nurses Association were surveyed. They were asked to agree or disagree (binary response) with the panel classification for each of the 37 DG emergency-sensitive conditions identified and provide free text responses to identify missing entities.

Results: A total of 719 ED providers (719 of 2,507, 29\%) completed the survey, of whom 470 were physicians (470 of $1,407,33 \%$ ) and 232 were nurses (232 of 1,100, $21 \%$ ). Information on professional status was not provided for 17 respondents. Of 37 DGs, 32 (e.g., A41 sepsis) were rated by more than $80 \%$ of respondents to be emergency-sensitive conditions. The remaining five DGs (e.g., E11 type 2 diabetes mellitus) were rated by 68.5 to $79.7 \%$ of the respondents to be emergency-sensitive conditions. Respondents suggested an additional 31 emergency-sensitive diagnoses.

Conclusion: We identified 37 emergency-sensitive DGs that had high face validity with emergency physicians and nurses, which will enable the calculation of an ED-HSMR.

\section{RÉSUMÉ}

Objectif: Dans une étude antérieure, un groupe d'étude pluridisciplinaire, canadien a relevé 37 groupes de diagnostics
(GD) selon la Classification internationale des maladies10-CA (adaptation canadienne), pour lesquels la prise en charge au service des urgences (SU) pouvait réduire la mortalité (maladies en phase critique au service des urgences [SU]). Toutefois, avant d'utiliser ces 37 GD pour calculer un ratio normalisé de mortalité hospitalière (RNMH) propre aux soins d'urgence, nous voulions en vérifier la validité apparente parmi les fournisseurs de soins d'urgence.

Méthode: Une enquête autoadministrée en ligne a été menée au sein du personnel médical et infirmier d'urgence, au Canada, entre le 22 novembre et le 31 décembre 2012. Tous les membres ( $\mathrm{N}=2507$ ) de l'Association canadienne des médecins d'urgence et de la National Emergency Nurses Association ont été invités à y répondre. On leur a demandé d'indiquer, pour chacun des 37 GD de maladies en phase critique au SU, s'ils étaient d'accord ou non (réponse binaire) avec le groupe d'étude sur la sélection proposée, et de donner des réponses en formulation libre pour l'ajout d'autres diagnostics.

Résultats: Au total, 719 (719 sur 2507; 29\%) fournisseurs de soins d'urgence, dont 470 médecins ( 470 sur $1407 ; 33 \%$ ) et 232 infirmières/infirmiers (232 sur 1100; 21\%), ont répondu au questionnaire. Dix-sept répondants n'ont pas fourni de renseignements quant à leur statut professionnel. Sur les 37 GD de maladies en phase critique au SU, 32 (ex.: A41 Sepsis) ont recueilli I'appui de plus de $80 \%$ des répondants; pour ce qui est des 5 autres GD de maladies en phase critique au SU (ex.: E11 - Diabète sucré de type 2), I'appui des répondants variait de $68.5 \%$ à $79.7 \%$. Enfin, les participants ont suggéré I'ajout de 31 diagnostics de maladies en phase critique au SU sur la liste préétablie.

Conclusion: La validité apparente de 37 GD de maladies en phase critique au SU a fait l'objet d'un large consensus au sein du personnel médical et infirmier d'urgence, ce qui a permis de calculer un RNMH-SU.

Keywords: cross-sectional studies, emergency service, health care, hospital, hospital mortality, outcome and process assessment, quality indicators, quality of health care

From the *Département de médecine d'urgence du CHU de Québec, Québec, QC; †Department of Community Health Sciences, University of Calgary, Calgary, AB; $\ddagger$ Department of Emergency Medicine, University of Calgary, Calgary, AB; and §Department of Critical Care, University of Calgary, Calgary, AB.

Correspondence to: Dr. Simon Berthelot, Department of Emergency Medicine, CHU de Québec-CHUL, 2705 Boul. Laurier, Québec, QC G1V 4G2; siberth@me.com.

This article has been peer reviewed

(c) Canadian Association of Emergency Physicians

DOI 10.2310/8000.2014.141466 
Many consensus statements have recommended monitoring mortality rates in patients after an episode of emergency department (ED) care as part of an ED performance assessment framework. ${ }^{1-5}$ To our knowledge, there is currently no validated risk adjustment model that can be used to monitor mortality after an ED episode.

Since 2007, the Canadian Institute for Health Information (CIHI) has reported a hospital standardized mortality ratio (HSMR) for each Canadian acute care facility. ${ }^{6}$ The HSMR methodology was developed in the 1990s in the United Kingdom to adjust and monitor mortality rates for patients admitted to hospital. Calculated from administrative data, it is the ratio of the observed number of deaths in a hospital in a specific year divided by the number of deaths expected if mortality was similar to that for patients admitted to comparable hospitals in a reference year. The Canadian HSMR includes patients with 1 of the 72 International Classification of Diseases-10-Canada (ICD-10-CA) Diagnosis Groups (DGs), accounting for $80 \%$ of in-hospital mortality in Canada as their most responsible diagnosis on hospital discharge. The CIHI calculates an overall HSMR and three additional ratios to further evaluate different patient populations (medical, surgical, and intensive care). None of these ratios focuses on the outcomes of patients admitted to hospital whose ED management would be expected to impact survival.

An expert panel selected 37 DGs in which ED management may potentially reduce mortality (emergencysensitive conditions) from the 72 DGs included in the Canadian HSMR. ' To calculate an HSMR variant more sensitive to the ED component of hospital care, further substantiation of this list by a broad spectrum of front-line emergency care providers is warranted. Our study objectives were to test the face validity of the 37 DGs selected by a consensus panel for inclusion in an ED-HSMR with ED care providers and identify missing diagnoses in the panel's selection.

\section{METHODS}

\section{Study design and population}

We conducted a self-administered cross-sectional web survey among Canadian emergency physicians and nurses. All members $(N=2,507)$ of the Canadian
Association of Emergency Physicians (CAEP) and the National Emergency Nurses Association (NENA) were surveyed.

\section{Survey content}

The survey instrument was available in English and French and contained the following domains of questions:

1. Respondents provided their demographic characteristics, including gender, years of work experience, profession, type(s) of hospital affiliation, and location(s) of practice.

2. Respondents were presented with the 37 emergencysensitive DGs previously identified by a Canadian multidisciplinary panel using the RAND/UCLA Appropriateness Method (RAM). ${ }^{7}$ They were asked for each DG whether they agreed or disagreed (binary answer) that ED care could reduce mortality for subsequently admitted patients with these diagnoses.

3. Respondents were invited to provide comments or suggest additional emergency-sensitive DGs.

To facilitate the rating process, respondents were provided with relevant definitions (e.g., emergencysensitive condition) and the ICD-10-CA description for each DG (http://fluidsurveys.com/s/survey-on-emergencysensitive-conditions-final/). A summary of the research protocol was available at the end of the questionnaire for participants who wanted additional information.

\section{Survey testing}

The web survey instrument was pilot tested with 28 emergency care providers (14 physicians and 14 nurses) to assess its relevance, appropriateness, intelligibility, and ease of administration. ${ }^{8}$ Median completion time among respondents was 5.22 minutes (interquartile range [IQR] 2.98-9.62 minutes). Test-retest reliability was conducted on 15 providers (8 physicians, 7 nurses) 1 week apart and showed greater than $80 \%$ intrarater agreement for all DGs. Clinical sensibility was assessed with the same 15 emergency care providers. ${ }^{9}$ The vast majority of respondents reported that the web survey tool had good clarity (14 of 15$)$, good utility (14 of 15$)$, good discriminability (10 of 13), high face validity (13 of 14), high content validity (12 of 15$)$, and minimal redundancy (14 of 15$)$. 


\section{Survey administration}

The survey was administered through CAEP and NENA membership email lists between November 22 and December 31, 2012, and was available in English or French. Compliant with each organization's policy for online survey administration, three reminders for the CAEP and none for the NENA were sent after the first email invitation. We were not able to track and describe the characteristics of the nonrespondents as CAEP and NENA membership lists are confidential. Survey administration and data collection were conducted using the online survey software provided by FluidSurveys version 5.0 (Fluidware Corporation, Ottawa, ON).

\section{Statistical analysis}

Survey responses were summarized as percentages of agreement (the proportion of ED care providers agreeing that a DG is emergency sensitive) with $95 \%$ confidence intervals. We specified a priori that a minimum of $50 \%$ agreement by survey respondents was required for candidate DGs to be included in an emergency-sensitive condition HSMR variant. The survey response rate was calculated as the proportion of partially or fully completed questionnaires over the total number of invitations sent. Stratified analyses were performed with the following respondents' characteristics: profession (nurses versus physicians), type(s) of hospital affiliation (academic versus nonacademic versus both), years of experience ( $\leq 5$ years versus $>5$ and $\leq 10$ years versus $>10$ years), and location of practice in Canada (east versus west versus Maritimes versus north). Two-way contingency tables and Fisher exact tests were used to assess significant differences between the subgroups. A two-sided $\alpha$ level of 0.0014 was used after applying a Bonferroni correction to each stratified analysis (0.05 of 37 comparisons). Respondents' suggestions of additional emergency-sensitive conditions, not included in the 37 DGs, were assessed using qualitative content analysis. ${ }^{10}$ Two authors (S.B. and E.S.L.) independently compiled and categorized the additional emergencysensitive conditions, compared and merged their lists, and resolved disagreements through discussion. Analyses were performed using Stata version 12.0 (StataCorp LP, College Station, TX). The study received ethics approval from the Conjoint Health

\begin{tabular}{|c|c|}
\hline Characteristic & $n(\%)^{*}$ \\
\hline \multicolumn{2}{|l|}{ Sex } \\
\hline Female & $339(47)$ \\
\hline Male & $318(44)$ \\
\hline Missing & $62(9)$ \\
\hline \multicolumn{2}{|l|}{ Profession } \\
\hline Physicians & $470(65)$ \\
\hline Nurses & $232(32)$ \\
\hline Missing & $17(2)$ \\
\hline Median number of years of work experience (IQR) & $13(7-20)$ \\
\hline Missing & 19 \\
\hline \multicolumn{2}{|l|}{ Survey language } \\
\hline English & $690(96)$ \\
\hline French & $29(4)$ \\
\hline \multicolumn{2}{|l|}{ Institution } \\
\hline Academic & $422(59)$ \\
\hline Nonacademic & $132(18)$ \\
\hline Both & $149(21)$ \\
\hline Missing & $16(2)$ \\
\hline \multicolumn{2}{|l|}{ Location of practice } \\
\hline Alberta & $116(16)$ \\
\hline British Columbia & $118(16)$ \\
\hline Manitoba & $32(4)$ \\
\hline Newfoundland and Labrador & $26(4)$ \\
\hline New Brunswick & $22(3)$ \\
\hline Northwest Territories & $3(0)$ \\
\hline Nova Scotia & $52(7)$ \\
\hline Nunavut & $3(0)$ \\
\hline Ontario & $242(34)$ \\
\hline Prince Edward Island & $6(1)$ \\
\hline Quebec & $51(7)$ \\
\hline Saskatchewan & $37(5)$ \\
\hline Yukon & $2(0)$ \\
\hline United States & $1(0)$ \\
\hline Missing & $8(1)$ \\
\hline
\end{tabular}

Research Ethics Board at the University of Calgary (E-24580).

\section{RESULTS}

\section{Characteristics of the participants}

Table 1 shows the characteristics of the survey respondents. A total of $719 \mathrm{ED}$ providers (719 of 2,507, $29 \%$ ) completed the survey. Of these respondents, 470 were physicians (470 of 1,407, 33\%) and 232 were nurses (232 of $1,100,21 \%)$. Information on the professional status was missing for 17 respondents. 
Table 2. Emergency department provider ratings of diagnosis groups as emergency-sensitive conditions

Diagnosis group

I21 Acute myocardial infarction

R57 Shock, not elsewhere classified

A41 Sepsis

E87 Other disorders of fluid, electrolyte, and acid-base balance

E86 Volume depletion

I26 Pulmonary embolism

K65 Peritonitis

J96 Respiratory failure, not elsewhere classified

146 Cardiac arrest

160 Subarachnoid hemorrhage

S06 Intracranial injury

N17 Acute renal failure

171 Aortic aneurysm and dissection

J18 Pneumonia

150 Heart failure

J80 Adult respiratory distress syndrome

K85 Acute pancreatitis

I24 Other acute ischemic heart disease

S72 Fracture of femur

I62 Other nontraumatic intracranial hemorrhage

K55 Vascular disorders of intestine

I61 Intracerebral hemorrhage

J44 Other chronic obstructive pulmonary disease

S32 Fracture of lumbar spine and pelvis

I63 Cerebral infarction

G93 Other disorders of brain

F05 Delirium, not induced by alcohol and other psychoactive substances

T82 Complications of cardiac and vascular prosthetic devices, implants, and grafts

J69 Pneumonitis due to solids and liquids

164 Stroke, not specified as hemorrhage or infarction

K56 Paralytic ileus and intestinal obstruction without hernia

L03 Cellulitis

K26 Duodenal ulcer

K92 Other diseases of digestive system

K72 Hepatic failure

K57 Diverticular disease of intestine

E11 Diabetes mellitus type 2
Emergency-sensitive condition $\%$ agreement $(95 \% \mathrm{Cl})^{*}$

$99.9(99.2-100.0)$

$99.8(99.1-100.0)$

$99.7(99.0-100.0)$

$98.7(97.5-99.4)$

$98.4(97.2-99.2)$

$98.4(97.2-99.2)$

97.7 (96.2-98.7)

97.2 (95.6-98.3)

96.7 (95.1-98.0)

96.2 (94.5-97.5)

$96.1(94.3-97.5)$

$96.0(93.8-97.1)$

95.7 (93.9-97.1)

94.8 (92.9-96.4)

$94.2(92.2-95.8)$

93.8 (91.7-95.6)

$93.2(91.0-95.0)$

93.1 (91.0-94.9)

$92.2(89.9-94.2)$

$91.0(88.6-93.0)$

$90.5(87.9-92.6)$

90.4 (88.0-92.6)

89.7 (87.1-91.9)

$89.2(86.6-91.5)$

$88.6(86.0-90.9)$

88.1 (85.5-90.5)

$87.4(84.7-89.8)$

$86.7(83.8-89.2)$

$85.4(82.6-88.0)$

84.7 (81.7-87.3)

$84.6(81.6-87.3)$

$80.4(77.1-83.4)$

79.7 (76.4-82.7)

78.4 (75.0-81.5)

$75.5(72.0-78.8)$

$73.4(69.8-76.7)$

$68.5(64.9-72.0)$

*Percentage of emergency department care providers agreeing with each Diagnosis Group selected by the panel.

Ninety-six percent of the participants (690 of 719 , 96\%) completed the survey in English. The majority of respondents practiced in Ontario (34\%), British Columbia (16\%), and Alberta (16\%).

\section{Face validity survey}

All 37 DGs presented in the survey were rated as emergency sensitive by the respondents (median percentage of agreement: $92.2 \%$, IQR: $86.7-96.1 \%$ )
(Table 2). Acute myocardial infarction (I21), shock not elsewhere classified (R57), and sepsis (A41) received the highest percentages of agreement. Thirty-two DGs were rated by more than $80 \%$ of respondents to be emergency-sensitive conditions. The remaining five DGs were rated by 68.5 to $79.7 \%$ of the respondents to be emergency-sensitive conditions. These included type 2 diabetes mellitus (E11), diverticular disease of intestine (K57), duodenal ulcer (K26), other diseases of the digestive system (K92), and hepatic failure (K72). 


Table 3. Additional diagnoses suggested as possible
emergency-sensitive conditions
Infectious diseases
1. Necrotizing fasciitis
2. Infections associated with the spine
Obstetric emergencies
1. Pelvic uterine hemorrhage
2. Pregnancy-associated bleeding
3. Birth and neonatal resuscitation
4. Incomplete abortion
5. Abruptio placentae
Toxicologic emergencies
1. Tricyclic
2. Methanol
3. MDMA (3,4-methylenedioxymethamphetamine)
4. Acetylsalicylic acid (acute or chronic)
1. Acetaminophen (acute or chronic)
1. Severe allergic reaction/anaphylaxis
6. Calcium blockers
1. Frail elderly
7. Beta-blockers
Psychiatric emergencies
1. Pulseless limb, arterial or major venous occlusions
1. Acute psychosis
2. Mania
3. Suicidal ideation
Environmental emergencies
1. Thermal emergencies
2. Major burns
3r. CO poisoning
1. Blunt or penetrating multisystem trauma
2. Major amputation
1. Airway obstruction
Ophthalmologic emergencies
1. Status asthmaticus
1.

\section{Stratified analyses}

Stratified analyses showed no difference in survey responses according to respondents' hospital affiliation (academic versus nonacademic versus both), years of work experience, or location of practice in Canada.
Statistically significant differences were observed between nurses' and physicians' responses for seven DGs. Survey results for both professions revealed high percentages of agreement for the same DGs.

\section{Suggested emergency-sensitive diagnoses}

Respondents proposed an additional 31 diagnoses that may be emergency-sensitive conditions (Table 3). Toxicologic $(n=7)$, obstetric $(n=5)$, environmental $(n=3)$, and psychiatric $(n=3)$ conditions were most frequently recommended.

\section{DISCUSSION}

Using the RAM, we previously identified 37 DGs where ED care (adequate diagnosis and/or appropriate therapy and/or timely care) could reduce the mortality of patients admitted to hospital. This national survey of Canadian ED providers demonstrated the selected DGs to have high face validity. Apart from these 37 DGs, 31 additional diagnoses were suggested by the survey respondents as potential emergency-sensitive conditions. The identification of emergency-sensitive DGs will enable the calculation of a HSMR specific to emergency care and help guide quality improvement efforts.

The "sensitive conditions" concept has been used for assessing health care system performance since the 1970s. Rutstein and colleagues first described "sentinel health events" where the incidence of preventable conditions inside a population was used to evaluate the quality of care offered to this community. ${ }^{11}$ Billings and colleagues later defined ambulatory care-sensitive conditions as "conditions-diagnoses for which timely and effective outpatient care can help reduce the risk of hospitalization." 12 Ambulatory care-sensitive conditions are now widely used in many jurisdictions as metrics to evaluate primary care. Carr and colleagues defined emergency care-sensitive conditions as those for which "high-quality emergency care makes a unique contribution to patient outcomes" and called for the development of a research agenda in the area. ${ }^{13}$ To our knowledge, we are the first to develop a list of emergency-sensitive conditions that we will use to calculate an ED-HSMR.

To be a valid measure of ED-related in-hospital mortality, the ED-HSMR has to be derived from diagnoses that are commonly treated in the ED, are frequently associated with in-hospital deaths, and are 
perceived to be clinically relevant to ED care providers. We conducted this national survey to ensure that our ED-HSMR would be calculated with a credible set of emergency-sensitive DGs. This HSMR variant will be calculated with 37 of the 72 DGs included in the CIHI HSMR. Sensitivity analyses will be conducted by including in the ratio calculation other potentially missing DGs identified with the consensus panel and the survey of ED care providers. Emergency-sensitive conditions may also be used as "sentinel" conditions that act as flags for quality problems or trigger performance reviews.

The HSMR is a risk adjustment model using indirect standardization to measure in-hospital mortality rates. Although adjusted for the type of institution and for important patient variables such as age, gender, comorbidities, in-hospital length of stay, transfer, and type of admission, this mortality ratio does not account for all possible confounders. Consequently, direct comparisons between hospitals using this metric are usually not recommended. ${ }^{14,15}$ The HSMR should be used either as a screening tool to detect significant hospital outliers or as a measure enabling institutions to better track, understand, and modify their own mortality trends over years. ${ }^{6}$ It should be considered a "big dot" measure designed to prompt more in-depth evaluation with other outcome and process-of-care indicators to better appraise its real meaning. Although still controversial, the HSMR has been reported to be a major incentive for improving care in many institutions. ${ }^{16}$

\section{LIMITATIONS}

This study has a number of limitations. First, our survey had 719 responses but a low response rate. The response rate raises the question of whether nonresponders have similar perceptions of the DGs. The large number of physicians and nurses working in diverse institutions, jurisdictions, and geographies that responded and strongly agreed with the panel ratings suggests that there is face validity to the DGs identified. Our response rate is comparable to those reported in previous surveys of health care professional society members in Canada and the United States. ${ }^{17,18}$

Second, using a Likert scale in our survey would have allowed for more discrimination between the DGs. Asking respondents to apply binary evaluations to a list of proposed to be emergency-sensitive conditions may have encouraged respondents to agree more frequently than with a more discriminative scale. The goal of our survey was to evaluate the face validity of the DG and identify potential DG misclassifications while keeping the web survey tool as simple as possible.

Finally, some of the 37 DGs, as defined in the ICD10-CA, represent heterogeneous conditions and diagnoses. The survey may have produced different results for a few DGs if the respondent knew the incidence of each subcode (e.g., E11.1 type 2 diabetes mellitus with coma) within the DG (e.g., E11 type 2 diabetes mellitus).

\section{CONCLUSION}

We determined that the 37 emergency-sensitive DGs previously selected by a national expert consensus panel for inclusion in an ED variant HSMR have high face validity. Emergency-sensitive conditions may help assess and guide quality improvement efforts in the ED.

Acknowledgement: We thank Ms. Jamie Boyd for her administrative support.

Competing interests: Grants were received from the Division of Emergency Medicine, University of Calgary, and Département de médecine familiale et de médecine d'urgence, Université Laval.

\section{REFERENCES}

1. Schull MJ, Guttmann A, Leaver CA, et al. Prioritizing performance measurement for emergency department care: consensus on evidence-based quality of care indicators. CFEM 2011;13:300-9, E328-43.

2. Beattie E, Mackway-Jones K. A Delphi study to identify performance indicators for emergency medicine. Emerg Med F 2004;21:47-50, doi:10.1136/emj.2003.001123.

3. Sibbritt D, Isbister GK, Walker R. Emergency department performance indicators that encompass the patient journey. Qual Manag Health Care 2006;15(1):27-38, doi:10.1097/ 00019514-200601000-00004.

4. Lindsay P, Schull M, Bronskill S, et al. The development of indicators to measure the quality of clinical care in emergency departments following a modified-Delphi approach. Acad Emerg Med 2002;9:1131-9, doi:10.1111/ j.1553-2712.2002.tb01567.x.

5. Jones P, Harper A, Wells S, et al. Selection and validation of quality indicators for the Shorter Stays in Emergency Departments National Research Project. Emerg Med Australas 2012;24:303-12, doi:10.1111/j.1742-6723.2012. 01546.x.

6. Canadian Institute for Health Information. RNMH: Une nouvelle méthode de mesure des tendances relatives à la mortalité hospitalière au Canada. Ottawa: ICIS;2007. Available at: https:// 
secure.cihi.ca/free_products/RNMH_hospital_mortality_ trends_in_canada_f.pdf.

7. Berthelot S, Lang ES, Quan H, et al. Identifying emergencysensitive conditions for the calculation of an emergency care inhospital standardized mortality ratio. Ann Emerg Med 2014;63:418-24, doi:10.1016/j.annemergmed.2013.09.016.

8. Burns KE, Duffett M, Kho ME, et al. A guide for the design and conduct of self-administered surveys of clinicians. CMAJ 2008;179:245-52, doi:10.1503/cmaj.080372.

9. Cook DJ, Guyatt GH, Jaeschke R, et al. Determinants in Canadian health care workers of the decision to withdraw life support from the critically ill. Canadian Critical Care Trials Group. FAMA 1995;273:703-8, doi:10.1001/jama. 1995.03520330033033.

10. Zhang Y, Wildemuth B. Qualitative analysis of content. In: Wildemuth B, editor. Applications of social research methods to questions in information and library science. Santa Barbara (CA): Greenwood Press; 2009. p. 308-19.

11. Rutstein DD, Berenberg W, Chalmers TC, et al. Measuring the quality of medical care. A clinical method. $N$ Engl 7 Med 1976;294:582-8, doi:10.1056/NEJM197603112941104.

12. Billings J, Zeitel L, Lukomnik J, et al. Impact of socioeconomic status on hospital use in New York City. Health Aff (Millwood) 1993;12(1):162-73, doi:10.1377/hlthaff.12. $\underline{1.162}$.

13. Carr BG, Conway PH, Meisel ZF, et al. Defining the emergency care sensitive condition: a health policy research agenda in emergency medicine. Ann Emerg Med 2010;56:4951, doi:10.1016/j.annemergmed.2009.12.013.

14. Ben-Tovim DI, Pointer SC, Woodman R, et al. Routine use of administrative data for safety and quality purposeshospital mortality. Med $\mathcal{F}$ Aust 2010;193(8 Suppl):S100-3.

15. Pouw ME, Peelen LM, Lingsma HF, et al. Hospital standardized mortality ratio: consequences of adjusting hospital mortality with indirect standardization. PloS One 2013;8(4):e59160, doi:10.1371/journal.pone.0059160.

16. Jarman B. In defence of the hospital standardized mortality ratio. Healthc Papers 2008;8(4):37-42; discussion 69-75, doi:10.12927/hcpap.2008.19974.

17. Grava-Gubins I, Scott S. Effects of various methodologic strategies: survey response rates among Canadian physicians and physicians-in-training. Can Fam Physician 2008;54:1424-30.

18. James KM, Ziegenfuss JY, Tilburt JC, et al. Getting physicians to respond: the impact of incentive type and timing on physician survey response rates. Health Serv Res 2011;46(1 Pt 1):232-42, doi:10.1111/j.1475-6773.2010. 01181.x.

\section{APPENDIX: WEB SURVEY INSTRUMENT}

Available at: http://fluidsurveys.com/s/survey-on-emer gency-sensitive-conditions-final/ 